\title{
All plug-in electric vehicles are not the same: Predictors of preference for a plug-in hybrid
} versus a battery-electric vehicle

\author{
Bradley W. Lane, $\mathrm{PhD}^{\mathrm{a}}$ (Corresponding Author) \\ Jerome Dumortier, $\mathrm{PhD}^{\mathrm{d}}$ \\ Sanya Carley, $\mathrm{PhD}^{\mathrm{b}}$ \\ Saba Siddiki, $\mathrm{PhD}^{\mathrm{c}}$ \\ Kyle Clark-Sutton ${ }^{\mathrm{e}}$ \\ John D. Graham, $\mathrm{PhD}^{\mathrm{b}}$
}

${ }^{a}$ School of Public Affairs and Administration, The University of Kansas

${ }^{\mathrm{b}}$ School of Public and Environmental Affairs, Indiana University

${ }^{c}$ Maxwell School of Citizenship and Public Affairs, Syracuse University

${ }^{\mathrm{d}}$ School of Public and Environmental Affairs, Indiana University-Purdue University Indianapolis

eRTI International, Research Triangle Park, NC

Abstract: This study analyzes data from a survey of drivers $(n=1,080)$ administered in late 2013

to assess factors that influence potential car buyers to consider two different types of plug-in

electric vehicles (PEVs) in the United States: plug-in hybrid electric vehicles (PHEVs) and

battery electric vehicles (BEVs). The results indicate distinct profiles of respondents preferring

PHEVs, which have a gasoline backup engine, versus battery BEVs, which rely solely on a

battery for power. Respondents interested in selecting a PHEV consider it more for its economic benefits, such as reduced gasoline and maintenance expenditures. Respondents preferring a BEV are drawn to its environmental and technological appeal. The absence of range anxiety for PHEV is a major factor influencing potential PEV buyers.

Keywords: Electric vehicles; sustainability; range anxiety; consumer preferences 


\section{Introduction and Background}

The advancement of electric vehicle technologies represents one of the most notable developments for surface transportation in the 21st century (Sierzchula, 2014). The increasing availability and use of plug-in electric vehicles (PEVs), the growing worldwide investment in related technological development and industrial production, and calls for a permanent alternative to the internal combustion engine (ICE), all suggest that PEVs will be long-term components of the future of transportation (Sperling, 2018a; Sperling, 2018b). Electrification of surface transportation is motivated by both environmental and energy-security objectives. Broad diffusion of PEVs could contribute to the sustainability of transportation by decreasing reliance on petroleum in transport, with the associated benefits of lowering urban air pollution and greenhouse gas emissions from the transportation sector and reducing economic vulnerability (Lane and Beeler 2017). Additionally, PEVs can encourage industrial development by enhancing the competitiveness of national and regional automotive industries, including their supply chains (Lane et al.. 2013).

The global stock of PEVs in use has grown from virtually zero in 2010 to more than two million in 2016 (IEA, 2017). In 2017, approximately 200,000 new PEVs were sold in the United States, equating to a 26\% increase over 2016 and a 72\% increase over 2015 (InsideEVs.com, 2018). The United States Environmental Protection Agency lists 13 battery electric vehicle (BEV) models and 18 plug-in hybrid electric vehicle (PHEV) models ${ }^{1}$ (US EPA Fuel Economy Guide, 2017). Many manufacturers and dealers, especially in metropolitan areas, now offer at

\footnotetext{
${ }^{1}$ PEVs can generally be divided into two categories: (1) plug-in battery-electric vehicles (BEVs) and (2) plug-in hybrid electric vehicles (PHEVs). BEVs, such as the Nissan Leaf or the Tesla Model S, rely solely on a battery for power that recharges through an electric socket. PHEVs, such as the Chevrolet Volt and the Toyota Prius Prime, rely on a battery and a gasoline engine that works either as a backup to the electric motor or in tandem with it. The Volt is sometimes called a range-extended BEV but for simplicity in this article we call it a PHEV.
} 
least one PEV model, and an increasing number of consumers have a basic knowledge of PEVs in contrast to when these vehicles first appeared on the mass market in the early 2010 s.

Although PEV sales are growing rapidly in the United States and globally, they account for a small share of total new vehicle sales (see IEA, 2017 for PEV penetration rates in different countries). Questions remain about how PEVs can penetrate the mass market (National Research Council, 2015). Much of the existing research and popular literature points to various factors that encourage or hinder the uptake of PEVs. However, limited attention has been paid to ascertaining whether potential car buyers have distinct preferences for PEVs with different performance and functional characteristics. BEVs are subject to a much more limited range on a single charge than PHEVs, which can travel longer distances and whose ICEs refuel in the same manner as conventional vehicles. The greater similarity of PHEVs to existing conventional vehicles suggests the possibility that these different types of PEVs may not diffuse in the same way. With expanded offerings in recent years of PHEVs and BEVs, research into how appeal to PEVs might vary across different forms of PEVs is especially warranted.

In this paper, we analyze data from a survey of 1,080 drivers across urban areas in the United States that was designed to capture potential car buyers' attitudes and preferences regarding different types of PEV technologies. In our analysis, we specifically examine whether individuals who are likely to purchase a vehicle in the near future - here defined as the next two years - indicating a preference for PHEVs are distinct in their profiles from those individuals who indicate a preference for BEVs. In doing so, we contribute to existing scholarship by offering a more nuanced discussion about which aspects of alternative vehicle technologies are most compelling and deterring to different types of consumers. 


\subsection{Overview of Prior Literature}

There is a large literature on the factors that are related to interest in, and adoption of, alternative-fueled vehicles, in particular PEVs. There are clear demographic factors that associate positively with PEV adoption. In a survey of U.S. urban residents, Carley et al.. (2013) found that younger, affluent, and educated individuals are more likely to purchase a PEV. Perceived ease-of-use (e.g., perceptions regarding vehicle range) and lifestyle compatibility (e.g., availability of charging infrastructure) are also factors shown to influence PEV adoption, particularly as they address key perceived shortcomings of the technology (Petschnig et al.., 2014, Moons and De Pelsmacker, 2015; Jansson, 2011; Graham-Rowe et al. 2012; Caparello and Kurani 2012). Direct prior experience with alternative-fueled vehicles, such as a conventional hybrid, also tends to encourage interest in PEVs (Axsen and Kurani 2013a, Carley, et al.. 2013; Skippon and Garwood, 2011; Moons and De Pelsmacker, 2015; Caperello and Kurani, 2012). Relatedly, social interaction, through which individuals hear about trusted peers' experience with vehicle technologies, also shapes car buying preferences (Mau et al.., 2008; Axsen and Kurani 2012). Individuals may also be drawn to alternative vehicles as their use may serve as a medium through which to convey pro-environmental attitudes or enthusiasm for new technologies (Axsen and Kurani, 2011). Finally, PEV adoption may also be related to other lifestyle choices, including financial management, activity and fitness, and having a strong sense of community (Heffner et al.., 2008).

Previous literature has also emphasized the importance of policy, such as rebates or tax incentives that minimize the cost of purchasing a PEV, in influencing consumer interest in PEVs (National Research Council, 2015). Other types of influential policy measures include free 
public charging stations, expedited permitting and rebates for the installation of home vehicle charging infrastructure, prioritized parking access in urban areas, and free access to highoccupancy vehicle or toll lanes (Gallagher and Muehlegger, 2011; Lane et al.., 2013; Lutsey et al.., 2015; Clark-Sutton et al. 2016; Coffman et al. 2016; Langbroek et al. 2016; Liao et al. 2016; Deshazo et al. 2017). Lastly, preferences for certain vehicle attributes may impact one's interest in buying a PEV (e.g., Moons and De Pelsmacker, 2015). Individuals that prioritize high fuel economy or environmental performance will be more likely to purchase a PEV than those that prioritize towing capacity, for example. A complication to the study of consumer preferences is the possibility that consumers may have a relatively poor understanding of fuel economy, and their calculations of vehicle operating costs and tradeoffs among choices are fraught with error (Dumortier et al. 2015; Rezvani, 2015). Particularly relevant to this research, Axsen et al. (2015) surveyed 1,754 Canadian consumers and found that PHEVs are preferred to BEVs, irrespective of the driving range of the vehicle. This is surprising and the authors hypothesize that this is either due to the difficulty for "buyers with little or no previous PEV [battery electric vehicle] experience...to place a value on a unit of electric-powered driving range" or their research design capturing a too narrow band of electric driving ranges. In general, they find that the choice of a PHEV is associated with pro-environmental and technology oriented lifestyles, while willingness-to-pay (WTP) for charging infrastructure is valued more highly for BEV than a PHEV, further suggesting difference in appeal to the two types of PEVs related to range.

\subsection{Knowledge Gaps and Contributions of this Study}


Previous research suggests that PEV purchase decisions are complex and multifaceted (National Research Council, 2015). The limited proliferation of PEVs into the vehicle market, despite supportive policies for industrial development and consumer purchase, offers some indication that consumers perceive them to have limited value. While existing scholarship offers valuable insight on the types of factors that shape consumer PEV decision making, it offers relatively little account for variation among interest in the different types of PEVs we see today. Factors along which PEVs exhibit variation include vehicle cost and performance. For example, Hardman et al. (2016) find significant differences among key attributes in intention to adopt a PEV based on whether the responded was a "low-end" adopter - interested in a smaller, less-costly PEV such as a Nissan Leaf - versus a "high end" adopter of a more expensive, higher performing PEV such as a Tesla Model S. Higgins et al. (2017) found drivers of interest in different types of PEVs vary by vehicle body size and type.

Perhaps most powerful is the role of vehicle range in between recharging or refueling, which differs substantially not only among BEV offerings, but also between PHEVs and BEVs. Though range anxiety is a commonly cited barrier to adoption, the daily travel needs and travel behavior of most households can be met by most PHEV and BEV models (Lane et al.. 2014, 2016; Liao et al. 2016). Needell et al. (2016) estimate that the energy requirements of about $87 \%$ of vehicle days could be met by a typical BEV without recharging during daily use. However, most consumers place a high value on many important convenience factors that the potential of having to stop and recharge a BEV inhibits, such as avoiding the time, stress, and hassle of locating and detouring to stations, or being able to travel long-distances. A BEV should be less appealing to many households than a PHEV, which does not force the same inconveniences since it has a conventional gasoline-powered motor as part of its powertrain. It is not surprising 
that consumers might examine BEVs and PHEVs carefully to determine whether they can meet their perceived individual and household needs for travel.

While there is relatively little work examining the differences in consumer preferences for PHEVs versus BEVs in the United States, some have alluded to or empirically demonstrated that differences exist (e.g., Axsen et al. 2015). Figenbaum and Kolbenstvedt (2016) study the case of Norway, which dominates internationally in penetration of PEVs into the vehicle market. There, BEVs and PHEVs are shown to appeal to different subsets of consumers: BEV owners are more likely to live in urban centers and own multiple vehicles, while PHEV owners are geographically dispersed and are more likely to live in single-vehicle households (Figenbaum and Kolbenstvedt, 2016). Additionally, recent evidence indicates that policies in different countries also vary in how much they promote BEVs versus PHEVs (IEA 2017).

The relative lack of research on differences in interest of different types of PEVs and the limited evidence internationally that such differences do exist suggests the need for further research into the attributes that motivate interest in different types of PEVs within the United States. We address this shortcoming through an analysis of a large sample survey of urban residents where we evaluate the selection of a PHEV or BEV in an-intent-to-purchase survey exercise. In our analysis, we specifically examine whether individuals who are likely to purchase a vehicle in the near future - here defined as the next two years - indicating a preference for PHEVs are distinct in their profiles from those individuals who indicate a preference for BEVs.

\section{Research Design}

We use a cross-sectional design to estimate the relationship between PEV type and respondent perceptions and characteristics. Our analysis is based on data gathered through a 15-minute 
online survey administered by Qualtrics in October and November, 2013, to a random sample of roughly 100 urban residents from each of the 32 largest metropolitan areas in the United States. ${ }^{2}$ In order to participate in the survey, respondents were required to be 18 years of age or older and have a valid driver's license. We chose urban areas because (1) vehicle miles traveled are lower than rural areas, which makes it more likely for urban consumers to choose a plug-in vehicle; (2) metropolitan areas are targeted by car manufacturers as roll-out places (Carley et al.., 2013); and 3) consumers in metropolitan areas are more likely to travel distances that are within the range of a PEV (National Research Council, 2015). The survey instrument elicited the perceptions and attitudes of each respondent toward PEVs (PHEVs and BEVs), conventional hybrid electric vehicles, and conventional ICE vehicles. Survey questions asked about the respondent's vehicle ownership history, agreement or disagreement with statements about PEVs, general travel behavior, preferences for certain vehicle attributes, and the influence of public policies on intent to purchase different types of vehicle technologies. It concluded with personal socio-economic and demographic questions.

The total sample included 3,199 respondents. In order to enhance the validity of our findings, we focus this analysis on the 1,080 respondents who expressed intention to purchase or lease a new vehicle in the two years following the administration of the survey. Upon starting the survey, people were asked whether they are interested in (1) a small car (example: Honda Civic) or midsize car (example: Chevrolet Malibu) or (2) a small SUV (example: Ford Escape) or crossover car (example: Toyota RAV4). This question was included to make the choice for consumers more realistic in terms of what type of car design they prefer. Both types were available as PEVs

\footnotetext{
${ }^{2}$ Atlanta, Austin, Baltimore, Boston, Bridgeport, Charlotte, Chicago, Dallas, Denver, Detroit, El Paso, Houston, Indianapolis, Jacksonville, Los Angeles, Memphis, Nashville, New York, Orlando, Philadelphia, Phoenix, Portland, Raleigh, Richmond, Sacramento, San Antonio, San Diego, San Francisco, Seattle, Sonoma County, Tuscon, and Washington
} 
at the time of the survey. Then, respondents were shown an explanation of four different propulsion systems: (1) a conventional internal combustion engine (ICE) gasoline powered vehicle; (2) a conventional hybrid car, with no plug-in for recharging the battery; (3) a plug-in hybrid vehicle (PHEV), and (4) a battery electric vehicle (BEV). The information included vehicle function, charging technology, and battery capacity. The respondents were then presented with the EPA fuel economy labels for gasoline, hybrid, plug-in hybrid, and electric vehicles. The templates for those labels were obtained from the EPA and filled with information about generic cars to avoid any bias by the respondents towards a particular car, and the placement of the labels was randomized for each respondent to eliminate anchoring effects. The objective of this approach was to make the exercise as realistic as possible, despite the survey setting. Insofar as consumers typically see EPA labels on vehicles when at the dealership or similar information on the internet, and since such information informs their purchase decisions, we sought to replicate this process by providing the EPA labels. The generic information on the vehicles was obtained from Al-Alawi and Bradley (2013). Following exposure to these labels, the respondents were asked to select their preferred vehicle for purchase or lease. Therefore, unlike many studies on PEVs and alternative-fuel vehicles, we narrow our respondents to those that indicated they are likely to acquire a new car in the near future, and whom are already somewhat educated about the tradeoffs and incentives associated with considering a PEV against a typical internal-combustion engine (ICE) automobile.

\subsection{Dependent Variable}

The dependent variable is a binary variable indicating selection of a specific type of electric vehicle powertrain when respondents were asked about their "intent to purchase or lease" their 
next vehicle after being exposed to the information intervention. Our dependent variable is coded ' 1 ' if, when given the choice, the respondent chose a PHEV as their preferred technology for purchase or lease. This means that for the PHEV models, the dependent variable equals zero if the respondent chooses a conventional gasoline, hybrid, or BEV as their preferred vehicle, and equals ' 1 ' for choosing a PHEV. For the BEV models, the dependent variable equals zero if the respondent chooses a conventional gasoline, hybrid, or PHEV as their preferred vehicle, and equals ' 1 ' for choosing a BEV. For the multinomial models used as robustness checks, the dependent variable equals ' 1 ' for the respondent's choice of powertrain, and ' 0 ' for all the others.

\subsection{Independent Variables}

As mentioned, the survey collected responses on a wide variety of possible factors that could influence one's decision to express intent to purchase or lease a particular type of vehicle. These are informed by the prior literature and existing theory on motivations of consumers to express interest in PEVs (e.g., Coffman et al. 2016, Liao at al 2017). The full set of variables is presented in Table 1.

[Insert Table 1 about here]

Several important constructs in the survey instrument overlap, and we transform these correlated variables into factor scores using principal component analysis (PCA). PCA allows us to identify an underlying latent variable that drives the answers of the respondents and reduces the variable space. Since we do not assume any theoretical model involving latent factors, our PCA is purely exploratory. We calculate Cronbach's alpha coefficients, which assesses how closely related the items in each group are. Values close to one are an indication that there is 
some underlying latent variable driving the explanatory variables in a group. We use varimax as the rotational strategy in the PCA and drop all factors with an Eigenvalue below one. We use the Kaiser-Meyer-Olkin to test the adequacy of using the factor scores to generate new factors.

Kaiser-Meyer-Olkin values that exceed 0.7 and 0.8 are middling and meritorious, respectively (Kaiser, 1974).

One set of constructs that overlapped involved policies and incentives, where we asked the respondents whether the availability of certain policies would make it more or less likely that they would choose a PEV for purchase or lease. The policies included various financial incentives, preferred parking, and privileged highway lane access. The policy variables all load onto a single policy factor in the factor analysis, as demonstrated in Table 2, so we include a single policy binary variable in the models.

[Insert Table 2 about here]

We also asked users whether they expressed preferences for certain vehicle attributes and characteristics. These included questions assessing vehicle purchase, maintenance, and insurance costs, dealer service and financing arrangements, fuel economy, vehicle appearance, performance, and comfort, seating and storage capacity, safety, and manufacturer reputation. These constructs also overlapped, and we conducted a PCA on these attributes; the results are reported in Table 3 below. The first factor "vehicle cost" encompasses all the economic and financial attributes of the car such as the sticker price, financing options, and fuel and maintenance costs. Attributes in the second factor, "vehicle design," are centered on design attributes and the driving experience. This factor includes the most disparate of vehicle attributes including appearance, luxury, and manufacturers' reputation. We label the third attribute as "vehicle utility," which represents the practical attributes of a vehicle such as seating capacity, 
cargo, and safety rating. The last factor, "vehicle ruggedness," includes towing capacity and 4wheel or all-wheel drive.

[Insert Table 3 about here]

\subsection{Estimation Method}

We use binary logistic regression with standard errors clustered by city to predict the selection of each type of PEV. We use separate models to examine PHEVs and BEVs in order to identify and compare the factors that influence a respondent's intent to purchase or lease. In our modeltesting, the variable representing the respondent currently having a "somewhat or very favorable" impression of a type of PEV absorbed much of the explanatory power of the model for that type of PEV. To enrich our results as well as understand what variables captured the underlying construct of favorability, we run models both including and excluding the predisposed favorability variables. Therefore, four models predicting selection of a type of PEV are run: (1) PHEV including a favorability variable; (2) BEV including a favorability variable; (3) PHEV excluding a favorability variable; and (4) BEV excluding a favorability variable. We display results for the model performance, coefficients, and marginal effects.

To check for the robustness of our results, we run a multinomial probit model that determines the consumers' choice among the four vehicle types: PHEV, BEV, conventional hybrid, and ICE. Similar to the binary logistic models, we run the model with and without the favorability variables. In the multinomial probit, we include the favorability variables for all vehicles and not just the vehicle of interest as in the logit model. As opposed to binary or multinomial logit models, the multinomial probit has the advantage that it does not assume the 
independence of irrelevant alternatives, which may be violated in assessing how consumers consider choosing a vehicle.

\section{Analysis and Results}

Summary statistics are presented in Table 4, and a breakdown of key demographic characteristics is presented in Table 5. After the removal of incomplete responses, the sample size is 977 for the logistic regression models and 971 for the multinomial probit model.

[Insert Table 4 and 5 about here]

\subsection{Results for Binary Logit Models, PHEV vs. BEV}

Table 6 displays the results of the logistic regression models and compares the results for the models including the variables for favorability predisposition ("Favorability") to the models excluding them. In all of the models, favorability is a significant predictor of the variation in the decision to choose a PHEV or BEV; removing the favorability variable reduces the pseudo- $\mathrm{R}^{2}$ of each model by approximately $5 \%$.

[Insert Table 6 about here]

In both the models that include and exclude pre-disposed favorability, consumers that value maintenance cost savings and that spend relatively more on gasoline are associated with interest in a PHEV. External factors of media information, hearing about PEVs from a non-PEV owner, and the presence of policies encouraging PEV ownership are positively associated with PHEV selection. Increasing age discourages the likelihood of selecting a PHEV. Two of the factors for vehicle characteristics, vehicle cost and vehicle design, are negatively associated with interest in choosing a PHEV. When we remove the variable for favorable predisposition toward 
PHEVs, awareness of charging stations becomes statistically significant, while the positive role of word of mouth from a non-PEV owner and the negative role of the "Vehicle Cost" factor are no longer statistically significant predictors.

For both the models that include and exclude the pre-disposed favorability variable, awareness of charging stations and belief that owning a BEV will improve one's impact on the environment are positively associated with BEV selection. Additionally, when one places a higher priority on vehicle cost attributes, as represented by the vehicle cost factor in our models, he/she is more likely to select a BEV for purchase or lease. Concerns that BEV technology will become outdated, exposure to advertisement of the vehicles, and reliance on an automobile for trips to work, school, or personal trips under 100 miles all discourage choosing a BEV. When pre-disposed favorability variable is removed, concerns about the range of a BEV discourage selection of a BEV, while previous experience owning an alternative fueled vehicle encourages interest in adopting a BEV.

\subsection{Results for Multinomial Probit Models, PHEV vs. BEV vs. Hybrid vs. ICE}

When we compare the results from the multinomial probit model, including the favorability variable presented in Table 7, to the binary logistic models, we find that our results are robust to changes in the models, and generally reflect the results from the binary logit models ${ }^{3}$. Previous experience owning an alternative-fuel vehicle encourages adoption of a plug-in electric vehicle. Desiring to have cutting edge technology encourages choosing a BEV, while needing to replace an existing vehicle with the next vehicle purchase and reliance on automobile for most daily trips

\footnotetext{
${ }^{3}$ A pseudo-R2 is not calculated for the multinomial probit models in Tables 7 and 8 . The observations are clustered by city, which removes the property of independence for each observation. Multinomial probit models also do not assume independent observations; therefore a pseudo-R2 is inappropriate and not calculated here; see Veall and Zimmerman (1996) for further discussion.
} 
makes BEV selection less likely. The exception is that prior ownership of an alternative fuel vehicle and agreement with the statement that PEVs are at the cutting edge of transportation technology become statistically significant in the multinomial probit models. Age discourages the purchase of a PHEV across all models. The amount that one spends on gasoline and agreement that plug-in vehicles save money on maintenance costs are both positively associated with PHEV selection. Three variables are statistically significant uniquely for the BEV: impact on environment, concerns about the range of the vehicle, and a reliance on a car for travel. The variable "vehicle cost" is positive for the hybrid and BEV vehicles, likely because consumers who are price-conscious may be attracted to the lower operating cost (gasoline or electricity, insurance, and maintenance) of these vehicles.

[Insert Table 7 and 8 about here]

Removing the favorability variable in Table 8 results in a few minor changes to the results, which parallel those seen in the binary logit models. With pre-disposed favorability removed, supportive policies are positively associated with hybrids, PHEVs, and BEVs. Supportive vehicle cost factors no longer encourage selection of a hybrid. Projecting a positive environmental image, the vehicle being at the cutting edge of technology, and vehicle ruggedness all become positively associated with PHEV choice, while time to recharge is negatively associated with PHEV choice. The variable for maintenance cost becomes significant and encourages selection of a BEV, while the availability of a level 2 public charger discourages selection of a BEV.

\section{Discussion}


The results of the models indicate that choosing a particular model of PEV is predicated upon already having a favorable impression of that type of PEV. Several other factors, however, are associated with one's intent to purchase or lease a PHEV or BEV. Most notably, there are stark differences between the factors that drive interest in a PHEV versus a BEV. Once the predisposition toward each type of PEV is removed, the only variables that are consistent across both PHEVs and BEVs are the awareness of charging stations and the presence of supportive policies for PEV purchases. Pre-disposed favorability thus appears to indicate enhanced knowledge and education about these key incentivizing factors.

Though often lumped together in the general category of PEV, both in popular literature as well as in prior research, the results show that PHEVs and BEVs are very different vehicles in the eyes of the consumer and interest in them comes from two different profiles of consumers. Stated interest in purchasing or leasing a PHEV appears largely based on practical, tangible utility, including the expressed importance of lower vehicle and fuel costs, the importance of vehicle design attributes, and the importance of subsidizing policies. These results suggest that the higher-price and limited type of vehicle designs that are available as PEVs—both of which were even more limited at the time when the survey was conducted in 2013 - disincentivizes interest in PHEVs. Positive exposure to knowledge about PEVs through media and word-ofmouth from non-PEV owners also suggest a process that is based in utilitarian rationality. A potential PHEV owner is more likely choosing between a conventional ICE vehicle and a PHEV, and requires some kind of financial edge - through such components as vehicle cost, savings on gasoline, or policies that reduce purchasing or operating expenses for the owner-or some positive information — through such components as knowledge of PEVs through media or wordof-mouth from a non-PEV owner - to push them toward a PHEV. 
Stated interest in purchasing a BEV appears based more on emotive, ideological concepts around the image and environmental benefits of such a vehicle. This conclusion is supported by the predisposed favorability variable as a positive predictor of BEV selection, accompanied only by perception that driving a PEV will improve one's impact on the environment. To the extent that interest in a BEV is based in economic utility, instead of being incentivized by the financial benefits as indicated by those interested in a PHEV, those interested in a BEV are disincentivized by the operating limits of those vehicles. Consumers that rely heavily on vehicle use will not purchase a BEV likely due to uncertainty about the ability of such a vehicle to meet their unanticipated vehicle needs. More practical concerns such as replacing an existing car with the next vehicle purchase and reliance on an automobile for most daily trips discourage interest in selecting a BEV.

The change in the variables that become significant when the measurement of predisposed favorability toward each type of PEV is removed further supports this interpretation. Favorability appears to capture the effect of awareness of supportive PEV policies, and awareness of level 2 public charging stations. This suggests that interest in the two types of PEVs remains differentiated by practical utility versus environmental ideology after controlling for knowledge of the most important factors related to purchase price, operating cost, and range anxiety. Even with awareness of charging stations by both those choosing a PHEV and a BEV, interest in the hybrid drivetrains remain driven by practical utility, while interest in a purely electric vehicle continues to be a function of more ideological factors. In essence, the potential BEV owner resembles the prototypical early-adopter, with interest based in ideology and environmental impact, and not in the financial or utility based components of the vehicle purchase (National Research Council, 2015). 
Word-of-mouth from non-PEV owners is consistent across PHEVs, and media information (but not advertisement) also drives interest in PHEVs; however, these are not influential for BEVs. This may additionally suggest that PHEVs are better positioned to bridge the early-adopter/early majority gap, since these factors are known predictors of interest in typical ICE vehicles (Carley et al.. 2013), and would indicate that PHEVs are a closer substitute than BEVs to ICE vehicles in the eye of the consumer.

\section{Conclusion}

Based on these findings, it appears that for plug-in electric vehicles to proliferate the mainstream automobile market, range anxiety is one of the top performance features to address. While our data were collected in late 2013, at a time when some electric vehicles had a shorter range, more recent research shows that range anxiety remains a widespread concern (e.g., Singer, 2016), and the range of most BEVs offered is still far shorter - and recharging (refueling) times far longer than their ICE counterparts. It is important to note that the concept of range anxiety, while frequently cited in the literature as a key variable in discouraging PEV adoption and particularly BEV adoption, still remains difficult to quantify. The daily travel behavior of the average driver involves distances that are within the range of most BEVs available. However, most people seem to place a high option value on the ability to travel long distances if needed. Some literature suggests there is a disconnect between people's knowledge about their own travel behavior and the capabilities of a PEV (Krause et al. 2013, 2016; Lane 2014, 2016). Additionally, our variable for car reliance — where respondents report using a personal vehicle for trips to work, school, or discretionary travel under 100 miles — is not significant for the PHEV model, but is significant and one of the stronger predictors discouraging selection of a BEV. Since this definition of car 
reliance covers most vehicle owners, it suggests that addressing range anxiety is one of the most essential performance components to advancing BEVs into the mainstream vehicle market.

Other significant factors found here have likely evolved and will continue to evolve with time. More manufacturers are offering more BEV and PHEV models, incentives and policies have matured with consumer knowledge and awareness of them increasing, charging infrastructure has been expanded, and the number of consumers who have prior experience with an alternative fuel vehicle has increased, all of which are significant variables encouraging adoption in our model. Meanwhile, average gasoline prices, which had been at record highs between 2011-2014, have dropped precipitously since then thru 2017 (EIA 2018), which means the effect of high household fuel expenditures on encouraging adoption may have slackened. Concerns about the technology becoming obsolete and a lack of appeal to the design features of PEVs may have changed with the maturity of and expansion of offerings. Future research should continue to examine the effect of these factors, on both the general population and on the new adopters of PEVs in recent years.

Amid the population of car buyers, there appear to be subpopulations that are amenable to a PEV of some kind. PHEVs appear to appeal to a subpopulation of vehicle owner that has what could be considered as more traditional household transportation needs, and may consider PHEVs as an option to reduce the transportation costs of the household. BEVs appear to appeal to a subpopulation that does not have transportation needs of a traditional household, and instead thinks about a vehicle from its technological and/or environmental components, while the limitations of the technology and expense of BEVs discourages interest in adopting one. The importance of understanding these subpopulations will likely grow as PEV technology advances, and other changes including shared mobility and vehicle automation continue to develop as part 
of the urban transportation landscape. This suggests that future research should focus more on the role of travel behavior in influencing driver range anxiety, as well as continue to identify and estimate different typologies of transportation users.

A final note is on the performance of the models in this paper, and how they relate to prior work. Much of the research on PEVs suggests that we have a clear understanding of the drivers of PEV adoption, specifically for an early adopter population. However, there are several factors that indicate this understanding may be overstated. The relatively low market penetration of PEVs is one of these, despite years of time for potential users to adopt, technology to advance and become cheaper, and investment in battery and PEV technology to develop. Additionally, there is still a large amount of random variation indicated in the pseudo-R2 of these models in the decision to select a mode of PEV technology. This suggests that significant developments remain to be made about the decision of an individual or household to adopt an alternative-fueled vehicle, particularly by the general population. These results help address this by identifying the differences between PEV technologies and highlighting the importance of modeling and estimating the interest in BEVs and PHEVs separately due to the different profiles of consumers that each appeals. 


\section{References}

1. Al-Alawi, B.M., Bradley, T.H. (2013). Total cost of ownership, payback, and consumer preference modeling of plug-in hybrid electric vehicles. Applied Energy103, 488-506.

2. Axsen J., \& Kurani, K.S. (2011). Interpersonal influence in the early plug-in hybrid market: observing social interactions with an exploratory multi-method approach. Transportation Research Part D, 16, 150-59.

3. Axsen, J., \& Kurani, K.S. (2012). Interpersonal influence within car buyers' social networks: applying five perspectives to plug-in hybrid vehicle drivers. Environment and Planning A, 44(5), 1047-1065.

4. Axsen, J., \& Kurani, K. S. (2013a). Developing sustainability-oriented values: Insights from households in a trial of plug-in hybrid electric vehicles. Global Environmental Change, 23, $70-80$.

5. Axsen, J; Bailey, J.; and Castro, M.A. (2015). Preference and lifestyle heterogeneity among potential plug-in electric vehicle buyers. Energy Economics, 50(C), pp. 190-201.

6. Carley, Sanya; Krause, Rachel M.; Lane, Bradley W.; and Graham, John D. (2013) Intent to purchase a plug-in electric vehicle: A survey of early impressions in large American cities. Transportation Research Part D: Transport and Environment, 18(1), pp. 39-45.

7. Caperello, N.D., \& Kurani, K.S. (2012). Households stories of their encounters with a plugin hybrid electric vehicles. Environment and Behavior, 44(4), 493-508. 
8. Clark-Sutton, K., Siddiki, S., Carley, S., Wanner, C., Rupp, J., \& Graham, J. D. (2016). Plugin electric vehicle readiness: Rating cities in the United States. The Electricity Journal, 29(1), $30-40$.

9. Coffman, Makena; Bernstein, Paul; and Wee, Sherilyn (2016). Electric vehicles revisited: A review of factors that affect adoption. Transport Reviews, 37(1), pp. 79-93

10. DeShazo, J. R., Sheldon, Tamara L., Carson, Richard T. 2017. Designing policy incentives for cleaner technologies: Lessons from California's plug-in electric vehicle rebate program. Journal of Environmental Economics and Management 84: 18-43.

11. Dumortier, Jerome; Siddiki, Saba; Carley, Sanya; Cisney, Joshua; Krause, Rachel M.; Lane, Bradley W.; Rupp, John; and Graham, John D. (2015) Effect of life cycle cost information disclosure on the purchase decision of hybrid and plug-in electric vehicles. Transportation Research Part A: Policy and Practice, 72(2015), pp. 71-86.

12. Energy Information Administration (EIA) Monthly Energy Review: June 2018 Edition. Accessed via website, https://www.eia.gov/totalenergy/data/monthly/, most recently 17 July 2018.

13. Environmental Protection Agency (EPA) 2017 Fuel Economy Guide: https://www.fueleconomy.gov/feg/epadata/17data.zip accessed 20 April 2017

14. Figenbaum, Erick and Kolbenstvedt, Marika (2016). Learning from Norwegian Battery Electric and Plug-in Vehicle Hybrid Vehicle Users. 1492/2016. Norwegian Center for Transport Research. https://www.toi.no/getfile.php?mmfileid=43161. 
15. Gallagher, K. S., \& Muellegger, E. (2011). Giving green to get green? Incentives and consumer adoption of hybrid vehicle technology. Journal of Environmental Economics and Management, 61, 1-15.

16. Graham-Rowe, E., Gardners, B., Abraham, C., Skippon, S., Dittmar, H., Hutchins, R., \& Stannard, J. (2012). Mainstream consumers driving plug-in battery-electric and plug-in hybrid electric cars: A qualitative analysis of responses and evaluations. Transportation Research Part A, 46, 140-152.

17. Hardman, S., Shiu, E., \& Steinberger-Wilckens, R. (2016) Comparing high-end and low-end early adopters of electric vehicles. Transportation Research Part A, 88(2016), 40-57.

18. Heffner, R., Kurani, K., \& Turrentine, T. (2008). Symbolism in California's early market for hybrid electric vehicles. Transportation Research D, 12(6), 396-413.

19. Higgins, C.D., Mohamed, M., Ferguson, M.R. (2017) Size matters: How vehicle body type affects consumer preferences for electric vehicles. Transportation Research Part A, 100(2017), 182-201.

20. Inside EVs. Monthly Plug-in Sales Scorecard. Accessed via http://insideevs.com/monthlyplug-in-sales-scorecard/, most recently 4/11/2017.

21. International Energy Agency. (2017). Global EV Outlook. Paris, France.

22. Jansson, J. (2011). Consumer eco-innovation adoption: Assessing attitudinal factors and perceived product characteristics. Business Strategy and the Environment, 20, 192-210.

23. Kaiser, H. F. (1974). An index of factorial simplicity. Psychometrika, 39(1), 31-36. doi:10.1007/bf02291575 
24. Krause, Rachel M.; Lane, Bradley W.; Carley, Sanya; Sperl, Jon; and Graham, John D. (2016) Assessing the demand for electric vehicles under future cost and technology scenarios. International Journal of Sustainable Transportation, 10(8), pp. 742-751

25. Krause, Rachel M.; Carley, Sanya; Lane, Bradley W.; and Graham, John D. (2013) Perception and reality: Public knowledge of plug-in electric vehicles in 21 US cities. Energy Policy, 63, pp. 433-440.

26. Lane, Bradley W.; Messer, Natalie; Hartman, Devin; Carley, Sanya; Krause, Rachel M.; and Graham, John D. (2013) Government promotion of the electric car: Risk management or industrial policy? European Journal of Risk Regulation, 2013(2) pp. 224-241.

27. Lane, Bradley W.; Krause, Rachel M.; Carley, Sanya; Graham, John D. (2016) The influence of travel behavior on the acceptance of commercially available alternative fueled vehicles: Evidence from major US cities. Proceedings of the Transportation Research Board (TRB) 95 ${ }^{\text {th }}$ Annual Meeting.

28. Lane, Bradley W.; Sherman, Colin P.; Sperl, Jon; Krause, Rachel M.; Carley, Sanya; Graham, John D. (2014) Beyond early adopters of plug-in electric vehicles? Evidence from fleet and household users in Indianapolis. Proceedings of the Transportation Research Board (TRB) $93^{\text {rd }}$ Annual Meeting.

29. Lane, Bradley W. and Beeler, Joseph. (2017) "Sustainable Transportation.” The Wiley-AAG International Encyclopedia of Geography: People, the Earth, Environment, and Technology.

30. Langbroek, Joram H. M., Franklin, Joel P., Susiol, Yusak O. 2016. The effect of policy incentives on electric vehicle adoption. Energy Policy 94: 94-103. 
31. Liao, Fanchao; Molin, Eric; and van Wee, Bert (2017) Consumer preferences for electric vehicles: A literature review. Transport Reviews 37(3), pp. 252-275

32. Long, J. S., Freese, Jeremy. (2017). Regression Models for Categorical Dependent Variables Using Stata. Stata Press, College Station, Texas.

33. Lutsey, N., Searle, S., Chambliss, S., \& Bandivadekar, A. (2015). Assessment of leading electric vehicle promotion activities in United States cities. International Council on Clean Transportation.

34. Mau, P., Eyzaguirre, J., Jaccard, M., Collins-Dodd, C., \& Tiedemann, K. (2008). 'The neighbour effect': simulating dynamics in consumer preferences for new vehicle technologies. Ecological Economics, 68(1), 504-516.

35. Moons, I., \& De Pelsmacker, P. (2012). Emotions as determinants of electric car usage intention. Journal of Marketing Management, 28(3-4), 195-237.

36. National Research Council. (2015). Overcoming Barriers to Deployment of Plug-In Electric Vehicles. National Academies Press. Washington, DC.

37. Needell, Zachary A.; McNerney, James; Chang, Michael T; and Trancik, Jessica E. Potential for widespread electrification of personal vehicle travel in the United States. Nature Energy. Vol. 1, September. 1-7.

38. Petschnig, M., Heidenreich, S., \& Spieth, P. (2014). Innovative alternatives take actionInvestigating determinants of alternative fuel vehicle adoption. Transportation Research Part $A, 61,68-83$. 
39. Rezvani, Z., Jansson, J., \& Bodin, J. (2015). Advances in consumer electric vehicle adoption research: A review and research agenda. Transportation Research Part D, 34, 122-136.

40. Sierzchula, W. (2014). Factors influencing fleet manager adoption of electric vehicles. Transportation Research Part D, 31, 126-134.

41. Singer, M. (2016). Consumer views on plug-in electric vehicles - national benchmark report. National Renewable Energy Laboratory.

42. Skippon, S. \& Garwood, M. (2011). Responses to battery electric vehicles: UK consumer attitudes and attributions of symbolic meaning following direct experience to reduce psychological distance. Transportation Research Part D, 16, 525-531.

43. Sperling, D. (2018a). Electric vehicles: Approaching the tipping point. Bulletin of the Atomic Scientists, 74.40.

44. Sperling, D. (2018b). Three Revolutions: Steering Automated, Shared, and Electrified Vehicles to a Better Future. Island Press. Washington, DC. 2018.

45. Veall, M.R. and Zimmermann, K.F. (1996). Pseudo-R2 measures for some common limited dependent variable models. Journal of Economic Surveys, 10 (3), 241-259. 